\title{
Balanço de Carbono - Viabilidade Econômica de Dois Sistemas Agroflorestais em Viçosa, MG
}

\author{
Fernando de Castro Neto ${ }^{1}$, Laércio Antônio Gonçalves Jacovine ${ }^{2}$, \\ Carlos Moreira Miquelino Eleto Torres², Silvio Nolasco de Oliveira Neto², \\ Mateus Matos de Castro ${ }^{2}$, Paulo Henrique Villanova ${ }^{2}$, Giselle Lima Ferreira ${ }^{2}$ \\ ${ }^{1}$ Universidade Federal de Lavras - UFLA, Lavras/MG, Brasil \\ ${ }^{2}$ Departamento de Engenharia Florestal - DEF, Universidade Federal de Viçosa - UFV, Viçosa/MG, Brasil
}

\section{RESUMO}

A carência de estudos sobre o balanço de carbono e viabilidade econômica em sistemas agroflorestais (SAF) motivaram este estudo. Foram avaliados um sistema agrissilvipastoril (SASP) composto por eucalipto, feijão e capim braquiária e um sistema silvipastoril (SSP) composto por eucalipto e capim braquiária, ambos aos 3 anos de idade. Para estimar a biomassa do componente arbóreo foi utilizado o método indireto e para a gramínea, o direto. As emissões de gases de efeito estufa (GEE) foram baseadas no guia de Inventários Nacionais de GEE. Foram calculados o Valor Presente Líquido (VPL) e a Taxa Interna de Retorno (TIR). Os dois sistemas tiveram balanço de carbono positivo. No SASP, o VPL encontrado foi de R $\$ 388,77$ e a TIR, de $21 \%$, os resultados positivos ocorreram devido à receita gerada pela venda do feijão. No SSP, o VPL foi de - R\$1.298,00 e a TIR, de $-2 \%$, considerando o corte das árvores aos 3 anos.

Palavras-chave: fluxo de caixa, gases de efeito estufa, biomassa.

\section{Carbon Balance and Economic Viability in Two Agroforestry Systems in Viçosa, MG}

\begin{abstract}
The lack of studies on carbon balance and economic viability in Agroforestry Systems (AFS) motivated this study. We evaluated an agrosilvopastoral system (SASP), composed of Eucalypt, beans and Brachiaria-grass; and a silvopastoral system (SSP), composed of Eucalypt and Brachiariagrass, both 3 years old. The tree biomass was estimated using the indirect method and the direct method was used to quantify the grass biomass. Greenhouse gas (GHG) emissions were based on the National Inventory tab of GHGs. The Net Present Value (NPV) and Internal Rate of Return (IRR) were calculated. Both systems had a positive carbon balance. The NPV in the SASP was $\$ 388.77$ and the IRR was $21 \%$. The positive results were due to revenue generated by the sale of beans. The SSP NPV was $-\$ 1,298.00$ and the IRR of $-2 \%$, considering the 3 years old trees cutting.
\end{abstract}

Keywords: cash flow, greenhouse gases, biomass. 


\section{INTRODUÇÃO}

Durante a 15a Conferências das Partes (COP 15), o Brasil assumiu o compromisso de reduzir, de forma voluntária, suas emissões de gases de efeito estufa (GEE), entre $36,1 \%$ e 38,9\% dos níveis de emissão de 2005, até 2020 (Brasil, 2011). As principais fontes de emissão de GEE no Brasil são oriundas do setor agropecuário, as quais no ano de 2012 representaram 37\% das emissões de $\mathrm{CO}_{2}$ e no país (Brasil, 2014).

Além disso, a atividade agropecuária é uma das principais contribuintes para o acúmulo de $\mathrm{CH}_{4}$ na atmosfera, devido a fermentação entérica do animal (Jiao et al., 2014; Hammond et al., 2016), que é a maior fonte de emissão do gás nesse setor, no Brasil (Cerri et al., 2016).

Para mitigar as emissões de GEE e cumprir as metas de redução estabelecidas, o governo federal criou o programa Agricultura de Baixo Carbono (ABC), que visa incentivar a expansão de tecnologias como a Integração Lavoura-Pecuária-Floresta e os Sistemas Agroflorestais (SAF) (Brasil, 2011).

Os SAF são definidos como sistemas de uso da terra que envolvem dois componentes principais, árvores ou arbustos em conjunto com pastagem e/ou cultura agrícola, com o objetivo de beneficiar interações ecológicas e trazer retorno financeiro para o produtor (Mosquera-Losada et al., 2009), funcionando como potenciais sumidouros de carbono (Torres et al., 2014; Monroe et al., 2016).

Nesse contexto, o objetivo do presente trabalho foi realizar o balanço de carbono em dois SAF bem como analisar a viabilidade econômica aos três anos de implantação.

\section{MATERIAL E MÉTODOS}

\subsection{Localização e caracterização da área de estudo}

O estudo foi conduzido em dois sistemas agroflorestais implantados em 2008 no município de Viçosa, MG $\left(20^{\circ} 45^{\prime} \mathrm{S}\right.$ e $\left.42^{\circ} 51^{\prime} \mathrm{W}\right)$. O clima da região é do tipo Cwa, segundo a classificação de Köppen, definido como clima subtropical úmido (Abreu et al., 2011).

\subsection{Sistema agrissilvipastoril com feijão}

$\mathrm{Na}$ propriedade rural estudada destinou-se uma área para o sistema agrissilvipastoril (eucalipto + feijão + capim braquiária/gado), implantado em dezembro de 2008, em uma unidade demonstrativa de 0,73 ha.

O plantio em covas do componente arbóreo foi realizado de forma manual, adotando-se o híbrido Eucalyptus urophylla $\mathrm{x}$ Eucalyptus grandis, no espaçamento de $8 \times 3 \mathrm{~m}$. Para o plantio do eucalipto utilizou-se $0,2 \mathrm{~kg}_{\text {cova }}{ }^{-1}$ de NKP (6-30-6). Três meses após o plantio, realizou-se adubação de cobertura com 0,160 kg planta ${ }^{-1}$ de NPK (20-5-20).

O plantio de capim braquiária (Brachiaria decumbens) e o plantio de feijão (Phaseolus vulgaris) foram realizados simultaneamente, com auxílio de plantadeira com tração animal específica para plantio direto. O espaçamento entre linhas do feijão foi de $60 \mathrm{~cm}$, com aplicação de $300 \mathrm{~kg} \mathrm{ha}^{-1}$ de NPK (8-28-16) e $200 \mathrm{~kg} \mathrm{ha}^{-1}$ de uréia, em cobertura. Após firmação do pasto foram utilizados $100 \mathrm{~kg} \mathrm{ha}^{-1}$ ano $^{-1}$ de uréia.

Ao final do ano 1 ocorreu a entrada do componente animal. O manejo de pastejo foi baseado na altura da forrageira, com o gado adentrando na área e pastejando até a gramínea ficar com $5 \mathrm{~cm}$ de altura.

\subsection{Sistema silvipastoril}

Outra área da propriedade destinou-se para o sistema silvipastoril (eucalipto + capim braquiária/gado), implantado em dezembro de 2008 em uma unidade demonstrativa com área de 1,90 ha. Foram adotados o mesmo material genético do componente arbóreo e o mesmo espaçamento do sistema anterior.

\subsection{Determinação da biomassa do eucalipto}

As características dendrométricas do componente arbóreo foram coletadas em julho de 2012. Nos sistemas estudados foram lançadas parcelas de $750 \mathrm{~m}^{2}$ ( $25 \times 30$ metros) distribuídas de forma aleatória, sendo que no sistema agrissilvipastoril foram lançadas $3 \mathrm{e}$ no silvipastoril, 4, devido a proporção escolhida de 1 unidade amostral a cada 0,5 ha.

Todas as árvores dentro das parcelas tiveram o CAP (circunferência com casca a 1,30 m) mensurados utilizando-se fita métrica, o DAP foi calculado com 
a divisão do CAP por $\pi$. A altura foi estimada com auxílio do hipsômetro Forest Vertex IV ${ }^{\circledR}$.

Para estimativa da biomassa acima do solo, utilizou-se o modelo Schumacher-Hall (logaritimizado) ajustado para um sistema agrissilvipastoril com feijão, presente na mesma propriedade (Equação 1), com coeficiente de derteminação $\left(\mathrm{R}^{2}\right)$ igual a 93,69.

$\ln B=-2,172+2,385 * \ln D A P+0,0005 * \ln H t$

em que: $\mathrm{B}=$ biomassa total, em $\mathrm{kg}$; DAP = diâmetro a altura do peito, em $\mathrm{cm}$; $\mathrm{Ht}=$ altura total, em $\mathrm{m}$; $\mathrm{Mu}(\mathrm{c})=$ massa de matéria úmida total no campo, em kg.

O carbono estocado na biomassa foi estimado por meio da multiplicação dos valores de biomassa encontrados pelo fator 0,47 , conforme recomendação do IPCC (2006).

\subsection{Determinação da biomassa do capim braquiária}

Para estimar a biomassa da pastagem foram lançados, de forma aleatória, 10 gabaritos de $1 \mathrm{~m}^{2}$. Todo o material vegetal presente em cada gabarito foi cortado rente ao solo, com uma tesoura de poda. O material foi acomodado em sacos de polietileno, pesado em campo com auxílio de uma balança de precisão e, em seguida, foram retiradas amostras de peso conhecido.

Essas amostram foram acondicionadas em sacos de papel e levadas para secagem em estufa de circulação forçada de ar, a uma temperatura de $65^{\circ} \mathrm{C}$, até a estabilização da massa de matéria seca (Ribeiro, 2007).

A determinação da biomassa seca no campo foi obtida por meio do método da proporcionalidade, tal qual utilizado por Soares \& Oliveira (2002).

O carbono da pastagem foi estimado, assim como no componente florestal, com a utilização do fator 0,47 .

\subsection{Inventário de emissões de GEE}

Os cálculos das emissões de GEE foram baseados nas metodologias (TIER 1) contidas no Guia de Orientação para Inventários Nacionais de Gases de Efeito Estufa (IPCC, 2006). Dessa forma, estimaram-se as emissões de GEE oriundas das fertilizações nitrogenadas e da criação de bovinos.

As emissões totais de $\mathrm{N}_{2} \mathrm{O}$ pelo uso de fertilizantes foram calculadas pelo somatório das emissões diretas e emissões indiretas de óxido nitroso (Equação 2). As emissões diretas são provenientes da adição de esterco animal em pastagens, uso de fertilizantes sintéticos, cultivo de plantas fixadoras de nitrogênio, pela incorporação no solo de resíduos de colheita e pela mineralização de nitrogênio associada ao cultivo de solos orgânicos (Equação 3). Já as emissões indiretas de $\mathrm{N}_{2} \mathrm{O}$ referem-se à porção de nitrogênio incorporado ao solo, que é volatilizada na forma de $\mathrm{NH}_{3}$ e $\mathrm{NO}_{\mathrm{x}}$ (Equação 4) e também perdida por lixiviação (Equação 5).

$$
\begin{aligned}
& E_{N 2 O}=E_{N 2 O_{d}}+E_{N 2 O_{i}} \\
& E_{N 2 O_{d}}=Q_{f} * F E_{N 2 O_{d}} * F_{N-N 2 O} \\
& E_{N 2 O_{v}}=\left(Q_{f} * F r a c_{g a s}\right) * F E_{N_{v}} * F_{N-N 2 O} \\
& E_{N 2 O_{l}}=\left(Q_{f} * F_{r a c_{\text {lixiv }} .}\right) * F E_{N_{l}} * F_{N-N 2 O}
\end{aligned}
$$

em que: $E_{N 2 O}=$ emissão de $\mathrm{N}_{2} \mathrm{O}$, em toneladas por hectare; $E_{N_{2} O_{d}}=$ emissão de $\mathrm{N}_{2} \mathrm{O}$ direta, em toneladas por hectare; $E_{N_{2} O_{i}}=$ emissão de $\mathrm{N}_{2} \mathrm{O}$ indireta, em toneladas por hectare; $Q_{f}=$ quantidade de fertilizante utilizada, em toneladas por hectare; Frac $_{\text {gas }}=$ fração de $\mathrm{N}$ volatilizada na forma de $\mathrm{NH}_{3}$ e $\mathrm{NO}_{x}$, em toneladas por hectare - foi adotado o default do IPCC (10\%); Frac $_{\text {lixiv. }}=$ fração de $\mathrm{N}$ lixiviado, em toneladas por hectare - foi adotado o default do IPCC (30\%); $F E_{N 2 O_{d}}=$ fator de emissão de $\mathrm{N}_{2} \mathrm{O}$ para emissão direta - foi adotado o default do IPCC (1\%); $F E_{N_{v}}=$ fator de emissão de $\mathrm{N}$ volatilizado - foi adotado o default do IPCC (1\%); $F E_{N_{t}}=$ fator de emissão de $\mathrm{N}$ lixiviado - foi adotado o default do IPCC $(2,5 \%) ; F_{N-N 2 O}=$ fator de conversão $\mathrm{N}_{-\mathrm{N}_{2}} \mathrm{O}$, massa específica do $\mathrm{N}_{2} \mathrm{O}$ sobre a massa específica do $\mathrm{N}_{2}(44 / 28)$.

Além disso, calculou-se a emissão do componente animal do sistema. Por se tratar de uma pastagem com manejo considerado médio, adotou-se 1 unidade animal (u.a.) por hectare. Este valor está de acordo com a informação fornecida pelo produtor.

O bovino emite GEE basicamente por fermentação entérica e pelo manejo de seus dejetos. A fermentação entérica é parte do processo digestivo natural dos herbívoros ruminantes, que ocorre de forma anaeróbica no aparelho digestivo dos animais (rúmen e retículo), gerando energia, $\mathrm{CO}_{2}$ e $\mathrm{CH}_{4}$ (CETESB, 2011). A magnitude dessas emissões dependente da quantidade e da qualidade do alimento ingerido, de seu grau de digestibilidade e da atividade física animal, além de fatores intrínsecos aos animais. 
De acordo com MCT (Brasil, 2010), no Brasil, em média, cada cabeça de gado criada em sistema extensivo a pasto emite entre 55 e $58 \mathrm{~kg} \mathrm{CH}_{4}$.ano ${ }^{-1}$. Em um sistema de integração lavoura-pecuária com pasto bem manejado, Esteves et al. (2010) quantificaram para cada animal uma emissão de cerca de $39 \mathrm{~kg} \mathrm{CH}_{4}$ ano $^{-1}$. Assim, adotou-se esse valor para cálculo das emissões de $\mathrm{CH}_{4}$ animal (Equação 6).

$E_{\mathrm{CH} 4}=Q_{A} * \mathrm{FE}_{\mathrm{CH}_{4}}$

em que: $E_{C H 4}=$ emissão de $\mathrm{CH}_{4}$, em toneladas por hectare por ano; $Q_{A}=$ quantidade de animais por hectare; $F E_{C H 4}=$ fator de emissão de $\mathrm{CH}_{4}$ por fermentação entérica.

Os resíduos dos animais nos sistemas são depositados junto à pastagem. Esse tipo de manejo gera quantidades pequenas de $\mathrm{CH}_{4}$, entretanto a emissão de $\mathrm{N}_{2} \mathrm{O}$ pode ser elevada. A urina do bovino, por exemplo, gera $80 \%$ de todo o $\mathrm{N}_{2} \mathrm{O}$ lançado na atmosfera pelo animal (Lessa, 2011). Desse modo, quantificou-se a emissão de $\mathrm{N}_{2} \mathrm{O}$ proveniente da deposição das fezes e urina do animal na pastagem da mesma maneira com que foi calculada a emissão de $\mathrm{N}_{2} \mathrm{O}$ pelo uso de fertilizantes.
Posteriormente, para conversão da emissão total de $\mathrm{CH}_{4}$ e $\mathrm{N}_{2} \mathrm{O}$ em $\mathrm{CO}_{2}$ e (dióxido de carbono equivalente), multiplicou-se o valor obtido pelo Potencial de Aquecimento Global do óxido nitroso e metano (Equação 7).

$E_{C O_{2 e .}}=E_{G E E} * P A G_{G E E}$

em que: $E_{\mathrm{CO}_{2}}=$ emissão de dióxido de carbono equivalente, em toneladas por hectare; $E_{G E E}=$ emissão de $\mathrm{CH}_{4} \mathrm{e}$ $\mathrm{N}_{2} \mathrm{O}$, em toneladas por hectare; $P A G_{G E E}=$ Potencial de Aquecimento Global do GEE - segundo o Solomon et al. (2007), o PAG do $\mathrm{N}_{2} \mathrm{O}$ é igual a 298 e do $\mathrm{CH}_{4}$, igual a 25.

Ao final, contabilizaram-se as emissões de GEE em toneladas de dióxido de carbono equivalente para cada atividade dos sistemas.

\subsection{Análise econômica}

Para realização da análise de viabilidade econômica dos sistemas estudados foram levados em consideração custos com insumos, mão de obra, aquisição de animais e as receitas oriundas da venda de bovinos, da madeira, ainda aos três anos, e do feijão (no caso do sistema agrissilvipastoril) (Tabela 1 ).

Tabela 1. Custos e receitas utilizados para análise da viabilidade econômica dos sistemas estudados.

Table 1. Costs and revenues used for analysis of economic feasibility studies of systems.

\begin{tabular}{|c|c|c|c|c|}
\hline \multirow{2}{*}{$\begin{array}{c}\text { OPERAÇÃO } \\
\text { CUSTOS }\end{array}$} & \multicolumn{2}{|c|}{ ANO DE OCORRÊNCIA } & \multicolumn{2}{|c|}{ CUSTO TOTAL (R\$ ha-1) } \\
\hline & SASP & SSP & SASP & SSP \\
\hline Covas & 0 & 0 & 100,00 & 100,00 \\
\hline Cupinicida & 0 & 0 & 12,48 & 12,48 \\
\hline NPK (6-30-6) & 0 & 0 & 127,33 & 70,74 \\
\hline NPK (8-28-16) & 0 & - & 390,85 & - \\
\hline NPK (20-5-20) & 0 & 0 & 89,78 & 89,78 \\
\hline Formicida em pó & 0 & 0 & 7,18 & 7,18 \\
\hline Formicida isca & 0 & 0 & 18,90 & 18,90 \\
\hline Formicida líquido & 0 & 0 & 3,20 & 3,20 \\
\hline Herbicida 2,4 - D & 0 & 0 & 11,20 & 11,20 \\
\hline Herbicida fluazifop-p-butil + fomesafen & 0 & - & 43,50 & - \\
\hline Herbicida glyphosate & 0 & 0 & 11,10 & 22,78 \\
\hline Herbicida glyphosate (coroamento) & 0 & - & 174,45 & - \\
\hline Herbicida glyphosate (dessecação) & - & 0 & 0,00 & 112,37 \\
\hline Herbicida glyphosate (feijão) & 0 & - & 224,74 & - \\
\hline Molibdênio & 0 & - & 1,00 & - \\
\hline Mudas de eucalipto & 0 & 0 & 187,78 & 187,78 \\
\hline Semente de capim braquiária & 0 & - & 90,30 & - \\
\hline Semente de feijão & 0 & - & 337,50 & - \\
\hline Ureia & 0 & - & 151,08 & - \\
\hline Aquisição de novilhos & 0 & 0 & 1565,30 & 1565,30 \\
\hline
\end{tabular}




\begin{tabular}{|c|c|c|c|c|}
\hline \multirow{2}{*}{$\begin{array}{c}\text { OPERAÇÃO } \\
\text { CUSTOS }\end{array}$} & \multicolumn{2}{|c|}{ ANO DE OCORRÊNCIA } & \multicolumn{2}{|c|}{ CUSTO TOTAL (R\$ ha') } \\
\hline & SASP & SSP & SASP & SSP \\
\hline Vacina contra aftosa (2 vezes/ano) & 0 & 0 & 15,00 & 15,00 \\
\hline Vacina contra carbúnculo (1 vez/ano) & 0 & 0 & 8,00 & 8,00 \\
\hline Vermífugo (2 vezes/ano) & 0 & 0 & 139,00 & 139,00 \\
\hline Sal mineral & 0 & 0 & 625,00 & 625,00 \\
\hline Sal comum & 0 & 0 & 70,00 & 70,00 \\
\hline Carrapaticida e bernicida & 0 & 0 & 4,60 & 4,60 \\
\hline Aplicação de adubo & 0 & 0 & 100,00 & 100,00 \\
\hline $\begin{array}{l}\text { Aplicação de herbicida (coroamento e } \\
\text { feijão) }\end{array}$ & 0 & 0 & 150,00 & 100,00 \\
\hline Aplicação de herbicida (dessecação) & 0 & 0 & 75,00 & 75,00 \\
\hline Aplicação de molibdênio & 0 & - & 50,00 & - \\
\hline Colheita feijão & 0 & - & 525,00 & - \\
\hline Combate à formiga & 0 & 0 & 250,00 & 250,00 \\
\hline Coroamento mecânico & 0 & 0 & 150,00 & 150,00 \\
\hline Coroamento químico & 0 & 0 & 100,00 & 100,00 \\
\hline Marcação e abertura de covas & 0 & 0 & 125,00 & 125,00 \\
\hline Plantadeira & 0 & - & 300,00 & - \\
\hline Plantio de braquiária & 0 & - & 50,00 & - \\
\hline Trilhagem & 0 & - & 210,00 & - \\
\hline Herbicida (coroamento) & 1 & 1 & 22,78 & 22,78 \\
\hline Coroamento mecânico & 1 & 1 & 150,00 & 150,00 \\
\hline Coroamento químico & 1 & 1 & 100,00 & 100,00 \\
\hline Vacina contra aftosa (2 vezes/ano) & 1 & 1 & 15,00 & 15,00 \\
\hline Vacina contra carbúnculo (1 vez/ano) & 1 & 1 & 8,00 & 8,00 \\
\hline Vermífugo (2 vezes/ano) & 1 & 1 & 139,00 & 139,00 \\
\hline Sal mineral & 1 & 1 & 625,00 & 625,00 \\
\hline Sal comum & 1 & 1 & 70,00 & 70,00 \\
\hline Carrapaticida e bernicida & 1 & 1 & 4,60 & 4,60 \\
\hline $1^{\text {a }}$ Desrama eucalipto & 2 & 2 & 50,00 & 50,00 \\
\hline Vacina contra aftosa (2 vezes/ano) & 2 & 2 & 15,00 & 15,00 \\
\hline Vacina contra carbúnculo (1 vez/ano) & 2 & 2 & 8,00 & 8,00 \\
\hline Vermífugo (2 vezes/ano) & 2 & 2 & 139,00 & 139,00 \\
\hline Sal mineral & 2 & 2 & 625,00 & 625,00 \\
\hline Sal comum & 2 & 2 & 70,00 & 70,00 \\
\hline Carrapaticida e bernicida & 2 & 2 & 4,60 & 4,60 \\
\hline $2^{\text {a }}$ Desrama eucalipto & 3 & 3 & 100,00 & 100,00 \\
\hline \multicolumn{5}{|l|}{ RECEITAS } \\
\hline Venda da madeira $\left(\mathrm{m}^{3}\right)$ & 3 & 3 & 1450,65 & 1222,75 \\
\hline Venda dos animais & 2 & 2 & 4695,90 & 4695,90 \\
\hline Produção de feijão & 1 & - & 4064,50 & - \\
\hline
\end{tabular}

A taxa de lotação considerada para o local foi de $1 \mathrm{UA} / \mathrm{ha}$ (UA = unidade animal $=450$ de peso vivo $)$ (Barcellos et al., 2008), adquiridos com 5 arrobas e comercializados ao final de 2 anos com 15 arrobas (Faria et al., 2015).

A taxa de juros utilizada foi a Selic, com referência a data de $11 / 7 / 2016$, cujo valor era de $14,15 \%$ a.a. (ao ano).

\subsubsection{Valor Presente Líquido - VPL}

O Valor Presente Líquido é definido como a soma algébrica dos valores descontados do fluxo de caixa a ele associado, conforme apresentado na Equação 8. Um projeto é considerado economicamente viável se seu VPL for positivo para determinada taxa de juros (Silva et al., 2008). 
$V P L=\sum_{j=1}^{n} \frac{R_{j}}{(1+i)^{j}}-\sum_{j=1}^{n} \frac{C_{j}}{(1+i)^{j}}$

em que: $\mathrm{VPL}=$ valor presente líquido; $\mathrm{Rj}=$ receita no ano $\mathrm{j} ; \mathrm{Cj}=$ custo no ano $\mathrm{j} ; \mathrm{i}=$ taxa de desconto; $\mathrm{j}$ = período de ocorrência do custo ou da receita; e $\mathrm{n}=$ duração do projeto, em anos.

\subsubsection{Taxa interna de retorno - TIR}

É a taxa de desconto que iguala o valor presente das receitas ao valor presente dos custos, ou seja, iguala o VPL a zero (Equação 9). Também pode ser entendida com a taxa percentual do retorno do capital investido (Silva et al., 2008).

$\sum R j(1+T I R)^{-j}=\sum C j(1+T I R)^{-j}$

em que: $\mathrm{R}=$ receitas do projeto $(\mathrm{R} \$) ; \mathrm{C}=$ custos do projeto $(\mathrm{R} \$) ; \mathrm{TIR}=$ taxa interna de retorno; $\mathrm{j}=$ duração do projeto (anos).

\section{RESULTADOS E DISCUSSÕES}

\subsection{Estoque de carbono nos sistemas agrissilvipastoril e silvipastoril}

Com base na equação ajustada, calculou-se a biomassa e estimou-se o estoque de carbono e $\mathrm{CO}_{2} \mathrm{e}$ dos sistemas (Tabela 2).

O sistema agrissilvipastoril apresentou maior estoque de carbono quando comparado ao sistema silvipastoril. Essa diferença pode ser explicada pela presença do feijão no sistema agrissilvipastoril, uma vez que a adubação e restos culturais desse componente podem melhorar a fertilidade do solo, elevando o acúmulo de biomassa nesse sistema. É importante destacar que não foi contabilizado o carbono no solo. Porém o feijão é fixador de nitrogênio e os resíduos do cultivo são deixados no terreno, o que pode aumentar o estoque de carbono no solo.
Os sistemas agrissilvipastoril e silvipastoril apresentaram incremento anual de carbono de 3,719 tC e $3,124 \mathrm{tC} \mathrm{ha}^{-1}$ ano $^{-1}$, respectivamente. No estudo realizado por Müller et al. (2009), foi estimado incremento de $1,43 \mathrm{tC} \mathrm{ha}^{-1}$ ano $^{-1}$ para um sistema silvipastoril misto, com eucalipto e acácia, em densidade de 105 árvores por hectare, menor em relação à do presente trabalho.

Valores próximos aos desta pesquisa foram observados em dois sistemas silvipastoris no município de Alegrete, RS, no qual Oliveira et al. (2008) estimou um incremento de carbono para um sistema silvipastoril com pinus, com densidade de 500 e 1.000 árvores por hectare. Nos sistemas com eucalipto o incremento foi de 3,40 tC e 3,82 tC ha ${ }^{-1}$ ano $^{-1}$.

Em Nova Odessa, SP, Gutmanis (2004) observou um incremento no sistema silvipastoril com pinus de $2,93 \mathrm{tC}$ e $5,30 \mathrm{tC} \mathrm{ha}^{-1} \mathrm{ano}^{-1}$, na densidade de 200 e 400 árvores por hectare, respectivamente. Valores esses que foram inferiores para menor densidade e superiores para maior densidade de árvores em relação aos deste trabalho.

Tsukamoto (2003) estimou um incremento de 7,67 tC ha ${ }^{-1}$ ano $^{-1}$ para um sistema agrissilvipastoril com eucalipto e arroz no município de Paracatu, MG, portanto, maior em relação ao observado nesta pesquisa.

\subsection{Inventário de emissões de GEE}

Para o cultivo do eucalipto no sistema agrissilvipastoril foram contabilizadas as emissões provenientes da adubação de plantio em 2008 e de cobertura em 2009, perfazendo um total de $0,168 \mathrm{tCO}_{2} \mathrm{eha}^{-1}$ (2,322\% do total).

Embora tenha sido utilizada menor quantidade de NPK por planta, a adubação de cobertura apresentou maior emissão em relação a de plantio, em função da concentração de nitrogênio no NPK utilizado em cobertura.

Para o cultivo de feijão, a adubação em cobertura feita em 2009 apresentou maior valor em relação à do plantio em 2008, totalizando $1,454 \mathrm{tCO}_{2 \mathrm{e}} \mathrm{ha}^{-1}$

Tabela 2. Biomassa, carbono e $\mathrm{CO}_{2}$ e do componente arbóreo (toneladas por hectare) para os dois sistemas.

Table 2. Biomass, carbon and $\mathrm{CO}_{2} \mathrm{e}$ (ton per hectare) for the two systems.

\begin{tabular}{lccc}
\multicolumn{1}{c}{ Sistema } & $\begin{array}{c}\text { Biomassa } \\
\left(\mathbf{t ~ h a ~}^{-\mathbf{1}}\right)\end{array}$ & $\begin{array}{c}\text { Carbono } \\
(\mathbf{t} \text { ha }\end{array}$ & $\begin{array}{c}\mathbf{C O}_{\mathbf{2}} \mathbf{e} \\
\left(\mathbf{t} \mathbf{h a}^{-\mathbf{1}}\right)\end{array}$ \\
\hline Agrissilvipastoril com feijão & 29,013 & 13,636 & 49,999 \\
Silvipastoril & 24,455 & 11,455 & 42,002 \\
Média & $\mathbf{2 6 , 6 7 9}$ & $\mathbf{1 2 , 5 3 9}$ & $\mathbf{4 5 , 9 7 7}$ \\
\hline
\end{tabular}


$(20,091 \%$ do total). Esta diferença ocorre devido à maior concentração de nitrogênio no NPK e da adição de ureia em cobertura.

Para a bovinocultura, foram contabilizadas as emissões a partir de 2009, ano em que foi inserido o gado no sistema, sendo responsável por uma emissão de 3,494 $\mathrm{tCO}_{2}$ e ha-1 ${ }^{-1}$ correspondente à $48,260 \%$ do total. Para o capim braquiária foram contabilizadas as emissões a partir do plantio, em 2008, obtendo-se uma emissão total de 2,123 $\mathrm{tCO}_{2} \mathrm{e} \mathrm{ha}^{-1}$, correspondente a $29,328 \%$ do total (Tabela 3 ).

Para o sistema silvipastoril, o cultivo do eucalipto foi responsável pela emissão total de $0,168 \mathrm{tCO}_{2} \mathrm{eha}^{-1}$, correspondente à $2,905 \%$ do total. Para a bovinocultura, obteve-se uma emissão total de $3,494 \mathrm{tCO}_{2} \mathrm{e} \mathrm{ha}{ }^{-1}$, correspondente à $60,393 \%$ do total. Já para o capim braquiária obteve-se uma emissão total de 2,123 $\mathrm{tCO}_{2} \mathrm{eha}^{-1}$, correspondente à $36,702 \%$ do total das emissões geradas por este sistema (Tabela 3).

A diferença em relação às emissões entre os sistemas está relacionada à adição do cultivo de feijão no sistema agrissilvipastoril. O ano de 2009 foi o que apresentou maior emissão devido à adubação em cobertura para o eucalipto e feijão, na unidade agrissilvipastoril, e do eucalipto, na unidade silvipastoril.

\subsection{Balanço de carbono}

Até a idade estudada os sistemas apresentaram balanço de carbono positivo. A unidade agrissilvipastoril com feijão apresentou estoque de 49,999 $\mathrm{tCO}_{2} \mathrm{e} \mathrm{ha}{ }^{-1}$ e, em contrapartida, estimou-se uma emissão de $7,240 \mathrm{tCO}_{2} \mathrm{e} \mathrm{ha}^{-1}$. Portanto, o sistema apresentou um balanço de carbono positivo de 42,759 $\mathrm{tCO}_{2} \mathrm{e} \mathrm{ha}^{-1}$.
O sistema silvipastoril, apresentou estoque de 42,002 $\mathrm{tCO}_{2} \mathrm{e} \mathrm{ha}{ }^{-1}$, emissão de GEE de 5,785 $\mathrm{tCO}_{2} \mathrm{e} \mathrm{ha}^{-1}$ e balanço de 36,217 $\mathrm{tCO}_{2} \mathrm{e} \mathrm{ha}^{-1}$. De posse desses dados foi possível estimar a quantidade de árvores necessárias para compensar as emissões provenientes das atividades dos sistemas.

Para o sistema agrissilvipastoril com feijão seriam necessárias 53 árvores (14,479\%) para compensar as emissões e havia 369 árvores, proporcionando excedente de 316 árvores. O sistema silvipastoril necessitaria de 46 árvores (13,773\%) para neutralizar as emissões e havia 333 árvores, excedente de 287 árvores. Em média, seriam necessárias 14,145\% das árvores para neutralização das emissões. Assim, os resultados evidenciaram que os sistemas foram capazes de neutralizar as emissões de GEE e ainda foram superavitários.

\subsection{Análise econômica}

Os resultados de VPL e TIR indicam que o sistema agrissilvastoril é a única alternativa economicamente viável (Tabela 4) nas condições que o estudo foi conduzido, já que trata-se de uma avaliação inicial, aos 3 anos de idade, pois nesses sistemas espera-se maior valor agregado da madeira ao longo dos anos.

A diferença encontrada entre os dois sistemas ocorreu em virtude da receita gerada pela venda do feijão no sistema agrissilvipastoril, o que resultou no VPL positivo para esse sistema.

O resultado negativo encontrado no sistema silvipastoril é oriundo da ausência de receitas nos primeiros anos do sistema, ou seja, para ele ser viável economicamente deverá ser considerado um horizonte maior (diferentemente dos 3 anos aqui considerados)

Tabela 3. Emissão de $\mathrm{CO}_{2}$ e em t.ha- ${ }^{-1}$ em cada ano, para os sistemas avaliados.

Table 3. Emission of $\mathrm{CO}_{2}$ e in t.ha ${ }^{-1}$ in every year for the systems evaluated.

\begin{tabular}{|c|c|c|c|c|c|c|c|c|}
\hline \multirow{2}{*}{ Sistema } & \multirow{2}{*}{ Cultura } & \multicolumn{6}{|c|}{ Emissão (t CO $\left.\mathrm{CO}_{2} \mathrm{ha}^{-1}\right)$} & \multirow{2}{*}{$\begin{array}{c}\text { Porcentagem } \\
(\%)\end{array}$} \\
\hline & & 2008 & 2009 & 2010 & 2011 & 2012 & Total & \\
\hline \multirow{3}{*}{ Silvipastoril } & Eucalipto & 0,047 & 0,121 & 0,000 & 0,000 & 0,000 & 0,168 & 2,905 \\
\hline & Bovinocultura & 0,000 & 0,975 & 0,975 & 0,975 & 0,569 & 3,494 & 60,393 \\
\hline & Braquiaria & 0,463 & 0,463 & 0,463 & 0,463 & 0,270 & 2,123 & 36,702 \\
\hline Total & & 0,510 & 1,560 & 1,438 & 1,438 & 0,839 & 5,785 & 100 \\
\hline \multirow{4}{*}{$\begin{array}{l}\text { Agrissilvipastoril } \\
\text { com feijão }\end{array}$} & Eucalipto & 0,047 & 0,121 & 0,000 & 0,000 & 0,000 & 0,168 & 2,322 \\
\hline & Feijão & 0,320 & 1,134 & 0,000 & 0,000 & 0,000 & 1,454 & 20,091 \\
\hline & Bovinocultura & 0,000 & 0,975 & 0,975 & 0,975 & 0,569 & 3,494 & 48,260 \\
\hline & Braquiaria & 0,463 & 0,463 & 0,463 & 0,463 & 0,270 & 2,123 & 29,328 \\
\hline Total & & 0,830 & 2,694 & 1,438 & 1,438 & 0,839 & 7,240 & 100 \\
\hline
\end{tabular}


Tabela 4. Valor Presente Líquido e Taxa Interna de Retorno dos dois sistemas estudados.

Table 4. Net Present Value and Internal Rate of Return of the two systems studied.

\begin{tabular}{lcc} 
& Sistema silvipastoril & $\begin{array}{c}\text { Sistema } \\
\text { agrissilvipastoril }\end{array}$ \\
\hline VPL & $-\mathrm{R} \$ 1298,00$ & $\mathrm{R} \$ 388,77$ \\
TIR & $-2 \%$ & $21 \%$ \\
\hline
\end{tabular}

para agregar valor à comercialização da madeira para serraria.

Tais resultados de viabilidade econômica dos sistemas são diferentes dos encontrados por Faria et al. (2015), que analizaram a viabilidade econômica de um sistema agrissilvipastoril constituído por eucalipto, milho, capim braquiária e o componente animal, no qual foi encontrado VPL de R\$3.222,25 ha/ano e TIR de $14,03 \%$.

\section{CONCLUSÕES}

Os sistemas agrissilvipastoris e silvipastoris apresentam um excedente de árvores quando se pensa na neutralização de carbono, permitindo inferir que os sistemas agroflorestais contribuem de forma efetiva para diminuir a concentração de gases de efeito estufa na atmosfera.

Além do benefício ambiental do balanço de carbono positivo, produtores podem agregar valor ao seu produto com o marketing ambiental, como a comercialização do boi neutro em carbono.

\section{AGRADECIMENTOS}

Agradecemos ao CNPQ e à FAPEMIG pela concessão de bolsas e financiamento da pesquisa, ao departamento de Engenharia Florestal e à Universidade Federal de Viçosa pela disponibilização das estruturas e ao Grupo de Estudos em Economia Ambiental - GEEA pelos ensinamentos.

\section{STATUS DA SUBMISSÃO}

Recebido: 22 abr., 2014

Aceito: 28 ago., 2016

\section{AUTOR(ES) PARA CORRESPONDÊNCIA}

\section{Fernando de Castro Neto}

Departamento de Ciências Florestais - DCF, Universidade Federal de Lavras - UFLA, CP 3037, CEP 37200-000, Lavras, MG, Brasil e-mail: fernandodecastro@hotmail.com

\section{REFERÊNCIAS}

Abreu RCR, Assis GB, Frison S, Aguirre A, Durigan G. Can native vegetation recover after slash pine cultivation in the Brazilian Savanna? Forest Ecology and Management 2011; 262(8): 1452-1459. http://dx.doi.org/10.1016/j. foreco.2011.06.046.

Barcellos AO, Ramos AKB, Vilela L, Martha GB Jr. Sustentabilidade da produção animal baseada em pastagens consorciadas e no emprego de leguminosas exclusivas, na forma de banco de proteína, nos trópicos brasileiros. Revista Brasileira de Zootecnia 2008; 37(spe): 1-17. http:// dx.doi.org/10.1590/S1516-35982008001300008.

Brasil. Ministério da Ciência e Tecnologia - MCT. Status de ratificação do protocolo de Kyoto [online]. Brasília: MCT; 2010. [citado em 2010 jan 10]. Disponível em: http://www. mct.gov.br/index.php/content/view/4457.html

Brasil. Ministério da Agricultura, Pecuária e Abastecimento - MAPA. Plano Setorial de Mitigação e de Adaptação às Mudanças Climáticas para a Consolidação de uma Economia de Baixa Emissão de Carbono na Agricultura. Brasília: MAPA; 2011. 75 p. Versão preliminar.

Brasil. Ministerio da Ciência, Tecnologia e Inovação MCTI. Estimativas anuais das emissões de gases de efeito estufa do Brasil. 2. ed. Brasília: MCTI; 2014. 190 p.

Cerri CC, Moreira CS, Alves PA, Raucci GS, Castigioni BA, Mello FFC et al. Assessing the carbon footprint of beef cattle in Brazil: a case study with 22 farms in the State of Mato Grosso. Journal of Cleaner Production 2016; 112: 2593-2600. http://dx.doi.org/10.1016/j.jclepro.2015.10.072.

Companhia Ambiental do Estado de São Paulo - CETESB. Inventário de emissão de metano pela pecuária (fermentação entérica e sistemas de manejo de dejetos animais) do estado de São Paulo, 1990 a 2008. In: Companhia Ambiental do Estado de São Paulo - CETESB. $1^{\circ}$ Relatório de Referência do estado de São Paulo de Emissões e Remoções Antrópicas de Gases de Efeito Estufa, período de 1990 a 2008. São Paulo: CETESB; 2011.52 p. Programa de Mudanças Climáticas do Estado de São Saulo - PROCLIMA.

Esteves SN, Bernardi ACC, Vinholis MM, Primavesi O. Estimativas da emissão de metano por bovinos criados em sistema de integração lavoura-pecuária em São Carlos - SP. São Carlos: Embrapa; 2010. 7 p. Circular Técnica.

Faria CMA, Silva ML, Ferreira LR, Neto SNO, Salles TT. Análise econômica de sistemas de recuperação e 
manutenção de pastagens com gado de leite. Revista Reflexões. 2015; 1: 85-103.

Gutmanis D. Estoque de carbono e dinâmica ecofisiológica em sistemas silvipastoris [doutorado]. Rio Claro: Universidade Estadual Paulista; 2004.

Hammond KJ, Crompton LA, Bannink A, Dijkstra J, Yáñes-Ruiz DR, O'Kiely P et al. Review of current in vivo measurement techniques for quantifying enteric methane emission from ruminants. Animal Feed Science and Technology 2016; 219: 13-30. http://dx.doi.org/10.1016/j. anifeedsci.2016.05.018.

Intergovernamental Panel on Climate Change - IPCC. Guidelines for National Greenhouse Gas Inventories. Japan: IGES; 2006.

Jiao H, Yan T, Wills DA, Carson AF, Mcdowell DA. Development of prediction models for quantification of total methane emission from enteric fermentation of young Holstein cattle at various ages. Agriculture, Ecosystems \& Environment 2014; 183: 160-166. http:// dx.doi.org/10.1016/j.agee.2013.11.004.

Lessa ACR. Produção de óxido nitroso e volatilização de amônia derivados da aplicação de urina e fezes bovinos em pastagens sobre Latossolo em Goiás [dissertação]. Seropédica: Universidade Federal Rural do Rio de Janeiro; 2011.

Monroe PHM, Gama-Rodrigues EF, Gama-Rodrigues AC, Marques JRB. Soil carbon stocks and origin under different cacao agroforestry systems in Southern Bahia, Brazil. Agriculture, Ecosystems \& Environment 2016; 221: 99-108. http://dx.doi.org/10.1016/j.agee.2016.01.022.

Mosquera-Losada MR, McAdam JH, Romero-Franco R, Santiago-Freijanes JJ, Rigueiro- Rodróguez A. Definitions and Components of Agroforestry Practices in Europe. Dordrecht: Springer; 2009. p. 3-19. Series Advances in Agroforestry v. 6.
Müller MD, Fernandes EN, Castro CRT, Paciullo DSC, Alves FF. Estimativa de acúmulo de biomassa e carbono em sistema agrossilvipastoril na Zona da Mata Mineira. Pesquisa Florestal Brasileira 2009; 60: 11-17.

Oliveira EB, Ribaski J, Zanetti ÉA, Penteado JF Jr. Produção, carbono e rentabilidade econômica de Pinus elliottii e Eucalyptus grandis em sistemas silvipastoris no Sul do Brasil. Pesquisa Florestal Brasileira 2008; 57: 45-56.

Ribeiro SC. Quantificação do estoque de biomassa e análise econômica da implementação de projetos visando a geração de créditos de carbono em pastagem, capoeira e floresta primária [dissertação]. Viçosa: Universidade Federal de Viçosa; 2007.

Silva ML, Jacovine LAG, Valverde SR. Economia florestal. 2. ed. Viçosa: Editora UFV; 2008.

Soares CPB, Oliveira MLR. Equações para estimar a quantidade de carbono na parte aérea de árvores de eucalipto em Viçosa, Minas Gerais. Revista Árvore 2002; 26(5): 533-539. http://dx.doi.org/10.1590/S010067622002000500002 .

Solomon S, Qin D, Manning M, Chen Z, Marquis M, Averyt $\mathrm{KB}$, et al. Climate change 2007- The physical science basis: Contribution of Working Group I to the Fourth Assessment Report of the Intergovernmental Panel on Climate Change. Cambridge: Cambridge University Press; 2007. 996 p.

Torres CMME, Jacovine LAG, Oliveira SN No, Brianezi D, Alves EBBM. Sistemas agroflorestais no Brasil: uma abordagem sobre a estocagem de carbono. Pesquisa Florestal Brasileira 2014; 34(79): 1-10. http://dx.doi. org/10.4336/2014.pfb.34.79.633.

Tsukamoto AA Fo. Fixação de carbono em um sistema agroflorestal com eucalipto na região do Cerrado de Minas Gerais [tese]. Viçosa: Universidade Federal de Viçosa; 2003. 